is comparable to the number of different authors in 1963 (242).

Another way to measure the size of the research community is to count the number of core authors. We defined someone as a core author if that person published two or more papers in a given year. As with other indexes of research activity, the number of core authors peaked in 1973 (54) and has been declining since. However, despite this decline, there were 39 core authors in 2000 , whereas there were only 12 core authors in 1953. In addition, the productivity of the core authors has remained remarkably stable. The mean number of publications per core author was 2.42 in 1953 and 2.31 in 2000.

\section{Discussion}

The results are noteworthy for several reasons. The data refute the contention that animal learning is becoming an extinct field. Our keyword searches in the PsycInfo and Medline databases showed either steady or increasing frequencies of papers dealing with animal learning topics between 1970 and 2000. This is hardly the pattern of results one would expect for a field that is dying out. These data also suggest that federal regulations, increased costs, and increased pressure from animal rights activists have not discouraged research in animal learning. The increasing number of papers on animal learning found in Medline was particularly striking and, no doubt, reflects an increasing number of researchers examining learning from neuroscience and biomedical perspectives.

In contrast to the results obtained from PsycInfo and Medline, detailed analyses of the data from the leading animal learning journals from 1953 to 2000 indicated that research activity has shown modest declines since 1973. However, research activity in 2000 , as measured in terms of the total number of experiments published, was still substantially higher than it was in 1953 or 1963. Thus, pessimism about the status of behavioral studies of learning is not warranted if research activity is considered over a longer period of time.

The increase in studies of learning in Medline versus the modest decline in the major behavioral journals in recent decades is also not grounds for much pessimism. These trends are bound to be reconciled in future patterns of research activity. Investigations of the physiological mechanisms of learning have to rest on a sound behavioral foundation. One cannot examine the physiological mechanisms of a behavioral process without first clearly understanding the phenomenon at the behavioral level. Rather than foretelling the further erosion of behavioral studies of learning, the growing interest in the neural and biological mechanisms of learning should underscore the continued need for sound behavioral analysis.

\section{REFERENCES}

Turville-Heitz, M. (2000, February). Violent opposition. Scientific American, 282, 32.

\section{NOTE}

1. The animal kingdom includes both human and nonhuman species. However, in discussions of animal research, the term animal has been used typically only in reference to nonhuman species. That usage is followed in the present paper.

(Manuscript received November 1, 2001; revision accepted for publication April 29, 2002.)

\title{
Call for Papers \\ Special Issue on Pavlovian Conditioning and Basic Associative Processes
}

The InternationalJournal of Comparative Psychology (edited by Mauricio Papini) is inviting manuscripts for a special issue entitled Pavlovian Conditioning and Basic Associative Processes, to be published in 2004. This issue will be devoted to studies examining the associative structures and processes of behavior in mammals and birds. Empirical studies are encouraged, although theoretical papers and review articles will be considered. Manuscripts should be approximately 20-30 pages long, not including figures, references, tables. The deadline for submission of manuscripts is March 31,2003. Three copies of manuscripts should be sent to the Guest Editor of this special issue: Todd R. Schachtman, Department of PsychologicalSciences, 210 McAlester Hall, University of Missouri, Columbia, MO 65211 (e-mail: schachtmant@ missouri.edu). 